\title{
Risk assessment of electricity transmission and distribution tariff regulation for power grid enterprises based on best-worst method and cloud model
}

\author{
Ze Qi ${ }^{1}$, Peipei You ${ }^{2}$, Rengcun Fang ${ }^{3}$, Zhao Xu², Yuxin Zou ${ }^{3}$ and Sen Guo ${ }^{1, *}$ \\ ${ }^{1}$ School of Economics and Management, North China Electric Power University, 102206 Beijing, China \\ ${ }^{2}$ Department of Finance, Accounting and Auditing Research, State Grid Energy Research Institute, 102209 Beijing, China \\ ${ }^{3}$ Economic and Technology Research Institute of State Grid Hubei Electric Power Company, 430077 Hubei province, China
}

\begin{abstract}
The electricity transmission and distribution tariff policy of the second supervision cycle in China has formulated a much better electricity transmission and distribution tariff supervision system. In this context, the research on the risk related to electricity transmission and distribution tariff regulation faced by power grid enterprises is helpful for power regulatory agencies and business operators to identify and avoid risks in time and promote the sustainable development of electric power industry. Firstly, the risk evaluation criteria system is established. Secondly, a risk evaluation model based on the best and worst method (BWM) and cloud model for electricity transmission and distribution tariff regulation is proposed. Finally, the risk level of power transmission and distribution tariff regulation faced by four provincial power grid enterprises is evaluated. The validity and practicability of the proposed model in this paper are proved by the empirical analysis.
\end{abstract}

\section{Introduction}

With the more clarified on regulatory boundary and increasing force of regulation in China, the electric power grid enterprises are faced with a closed loop regulatory system and increasingly strict regulatory environment, which will face more uncertain risks. Therefore, it is urgent to research the risks of electricity transmission and distribution tariff regulation for power grid enterprises, which can help the power regulatory agencies and business operators to identify and avoid risks in time and promote the sustainable development of electric power industry under the electricity transmission and distribution tariff regulation environment.

Currently, most researches on the risks faced by electric power grid enterprise focus on the power grid operation, investment and so on. $\mathrm{Li}$, et al proposed that it was necessary to establish a reasonable feed-in tariff system for wind power and strengthen the commercialization and marketization of wind power operation management so as to cope with the operational risks faced by current power grid enterprises in the management of wind power projects[1]. For the investment risk, Pop, et al identified the technology of the company, the delay delivery of the electric facility and the aging of transmission assets as the key factors that affect the Romanian electric power enterprises on their investment decision[2].

However, the risks of electricity transmission and distribution tariff regulation for power grid enterprises have been rarely studied, especially that in China case has not been studied to the best of our knowledge. Therefore, this paper will use the BWM and cloud model to carry out risk assessment of electricity transmission and distribution tariff regulation for power grid enterprises in China.

\section{Risk evaluation index system construction}

It is of great significance to evaluate the risks of electricity transmission and distribution tariff regulation for power grid enterprises and to establish appropriate risk evaluation index system. The specific process of constructing the risk evaluation index system of electricity transmission and distribution tariff regulation for power grid enterprises in this paper is as follows:

Firstly, to build the risk evaluation index system of electricity transmission and distribution tariff regulation for power grid enterprises, an expert panel is set up, which includes three managers in the electricity enterprise, three academic scholars majored in energy policy. Then, according to the relevant electricity transmission and distribution tariff policies and expert panel's suggestion, seven criteria are determined, including ineffective asset separation risk (C1), grid investment constraint risk (C2), effective asset management risk (C3), electricity transmission and distribution cost implementation deviation risk(C4), grid investment execution deviation risk (C5), enterprise

* Corresponding author: guosen@ncepu.edu.cn 
operational risk (C6), and enterprise performance appraisal risk (C7).

\section{Risk assessment model based on the best-worst method and cloud model}

Based on the best-worst method and cloud model, this paper builds a risk assessment model for electricity transmission and distribution tariff regulation of power grid enterprises. Among them, the best-worst method is used to determine the weight of the risk assessment index of power transmission and distribution tariff regulation for power grid enterprises, and the cloud model is used for the comprehensive integration of the risk of power transmission and distribution tariff regulation for power grid enterprises. The specific principles of the risk assessment model of electricity transmission and distribution tariff regulation for power grid enterprises constructed in this paper are described as follows.

\subsection{Best-worst method}

The Best-worst method was proposed by Jafar Rezaei in 2015[3]. The specific steps to determine the weight of the risk assessment index of power transmission and distribution tariff regulation of power grid enterprises by using the best-worst method are as follows[4]:

Step 1: Determine a group of evaluation criteria $\left\{c_{1}, c_{2}, \ldots, c_{n}\right\}$, and determine the optimal criterion $c_{B}$ and the worst criterion $c_{W}$;

Step 2: Use numbers 1 to 9 to evaluate the degree to which the optimal criterion $c_{B}$ is superior to other indexes, and the result is expressed by vector as follows:

$$
A_{B}=\left(a_{B 1}, a_{B 2}, \ldots, a_{B n}\right)
$$

Where $a_{B j}(j=1,2 \ldots n)$ is the degree to which the optimal criterion is better than the $j$ th criterion, known that $a_{B B}=1$;

Step 3: Use numbers 1 to 9 to evaluate the degree to which other criterion are better than the worst criterion $c_{W}$, and the results are expressed by vector as follows:

$$
A_{W}=\left(a_{1 W}, a_{2 W}, \ldots, a_{n W}\right)
$$

Where $a_{i W}(i=1, \ldots, n)$ is the degree to which the $i$ th criterion is better than the worst criterion, which can be known that $a_{W W}=1$;

Step 4: Calculate the optimal weight of each criterion $\boldsymbol{\omega}=\left(\omega_{1}^{*}, \omega_{2}^{*}, \ldots, \omega_{n}^{*}\right)$.The specific calculation method is as follows:

$$
\begin{aligned}
& \min \xi \\
& \text { s.t. } \\
& \left|\frac{w_{B}}{w_{j}}-a_{B j}\right| \leq \xi, \\
& \left|\frac{w_{j}}{w_{w}}-a_{j W}\right| \leq \xi, \\
& \sum_{j} w_{j}=1 \\
& w_{j} \geq 0, j=1,2 \ldots n
\end{aligned}
$$

The optimal weight of each criterion $\left(\omega_{1}^{*}, \omega_{2}^{*}, \ldots, \omega_{n}^{*}\right)$ can be obtained by solving the above equation, and the consistency of the final result can be verified by Equation(4).

$$
C R=\frac{\xi}{\mathrm{CI}}
$$

Where CI is a fixed corresponding consistency index, and different values are taken according to the value of $a_{B W}$. Specific values are shown in Table 1 .

Table 1. Consistency index

\begin{tabular}{cccccccccc}
\hline$a_{B W}$ & 1 & 2 & 3 & 4 & 5 & 6 & 7 & 8 & 9 \\
$\mathrm{CI}$ & 0 & 0.44 & 1.00 & 1.63 & 2.30 & 3.00 & 3.73 & 4.47 & 5.23 \\
\hline
\end{tabular}

\subsection{Cloud model}

As an uncertain model of qualitative and quantitative transformation, the cloud model can fully reflect the randomness and fuzziness of language concepts, and is an effective tool to achieve qualitative and quantitative transformation[5].

Let $\mathrm{U}$ be the field of real numbers, $\mathrm{C}$ is a qualitative concept existing on $\mathrm{U}, x \in C$ is a random realization on $\mathrm{U}, \quad \mu_{A}(x) \in[0,1]$ is a random number with stable tendency related to $\mathrm{x}$, indicating the degree to which $\mathrm{x}$ belongs to $\mathrm{U}$. The distribution of $\mathrm{x}$ in the domain $\mathrm{U}$ is called a cloud, and each $\mathrm{x}$ is called a cloud droplet. Each cloud has three digital characteristics: expectation, entropy and hyperentropy. The cloud and its digital features are mapped to each other, and the given digital features can generate the cloud through a forward generator. The steps of the forward cloud generator algorithm are as follows[6]:

(1) Input: three eigenvalues $E_{x}, E_{n}, H_{e}$;

(2) Generates a normal random number $\overline{\mu_{i}} \sim\left(E_{n}, H_{e}\right)$;

(3) Generates a normal random number $x_{i} \sim\left(H_{e}, \overline{\mu_{i}}\right)$;

(4) Calculate the membership degree following the normal distribution $N\left(E_{x}, E_{n}\right)$ at $\mu_{i}$ :

$$
\mu_{i}=e^{-\frac{\left(x_{i}-E x\right)^{2}}{2 \overline{\mu^{2}}}}
$$

(5) Output: cloud drops $\left(x_{i}, \mu_{i}\right)$;

The detailed steps for the comprehensive integration of electricity transmission and distribution tariff regulation risks of power grid enterprises by using cloud model are as follows. 
Step 1: Build the standard evaluation concept cloud.

First of all, the concept cloud of standard evaluation should be constructed. The standard grades corresponding to the score interval of each criteria is shown in Table 2. For risk assessment using cloud model, there are two layers of index evaluation structure, namely target layer and first level index. The target layer is the final evaluation level of the power grid company, and the result is obtained through the combination of comprehensive cloud and index weight for the evaluation of first-level indexes. The first level indicators are the seven risk criteria described above.

Table 2. Criteria risk grade classification

\begin{tabular}{cccccc}
\hline \multirow{2}{*}{$\begin{array}{c}\text { The } \\
\text { index }\end{array}$} & \multicolumn{5}{c}{ Grade of evaluation standard } \\
\cline { 3 - 5 } name & {$[100,90)$} & {$[90,80)$} & {$[80,70)$} & {$[70,60)$} & $\leq 60$ \\
& & & & & \\
\hline The & & & & & \\
target & Very & High & Medium & Low & Very \\
layer & high D1 & D2 & D3 & D4 & Low D5 \\
C0 & & & & & \\
C1 & Very & High & Medium & Low & Very \\
& high D1 & D2 & D3 & D4 & Low D5 \\
C2 & Very & High & Medium & Low & Very \\
& high D1 & D2 & D3 & D4 & Low D5 \\
C3 & Very & High & Medium & Low & Very \\
& high D1 & D2 & D3 & D4 & Low D5 \\
C4 & Very & High & Medium & Low & Very \\
& high D1 & D2 & D3 & D4 & Low D5 \\
C5 & Very & High & Medium & Low & Very \\
& high D1 & D2 & D3 & D4 & Low D5 \\
C6 & Very & High & Medium & Low & Very \\
& high D1 & D2 & D3 & D4 & Low D5 \\
C7 & Very & High & Medium & Low & Very \\
& high D1 & D2 & D3 & D4 & Low D5 \\
\hline
\end{tabular}

Set the upper and lower boundary values of index $C_{g}(g=0, \ldots, 5)$ corresponding to level $D_{f}(f=1, \ldots, 5)$ as $l_{\mathrm{g} f}$ and $n_{g f}$, respectively. Thus, the normal cloud corresponding to this level can be obtained.

$$
\begin{aligned}
& E_{x_{g f}}=\left(l_{g f}+n_{g f}\right) / 2 \\
& E_{n_{g f}}=\frac{n_{g f}-l_{g f}}{2.355}
\end{aligned}
$$

Superentropy $H_{e}$ is usually set as 0.5 based on experience. The conceptual cloud number characteristics of the standard ratings corresponding to each rating range were obtained: high $(100,10 / 3,0.5)$, high $(85,5 / 3$, $0.5)$, medium $(75,5 / 3,0.5)$, low $(65,5 / 3,0.5)$ and very low $(0,20,0.5)$. Figure 1 shows the resulting standard evaluation concept cloud. cloud.

Step 2: Calculate the grid company risk integrated

The comprehensive cloud of a certain power grid company's risk assessment level is the target layer comprehensive cloud. For the target layer comprehensive cloud, considering the correlation between first-level indicators, the digital characteristics of the comprehensive cloud can be obtained by the following formula.

$$
\begin{gathered}
E_{x}=\frac{\sum_{g=1}^{5} E_{x_{g}} * E_{n_{g}} * \omega_{g}}{\sum_{g=1}^{5} E_{n_{g}} * \omega_{g}} \\
E_{n}=\sum_{g=1}^{5} E_{n_{g}} * \omega_{g} \\
H e=\frac{\sum_{g=1}^{5} H e_{g} * E n_{g} * \omega_{g}}{\sum_{g=1}^{5} E_{n_{g}} * \omega_{g}}
\end{gathered}
$$

The risk level of a power grid company can be obtained by comparing the position of comprehensive cloud and standard concept cloud according to digital features drawing.

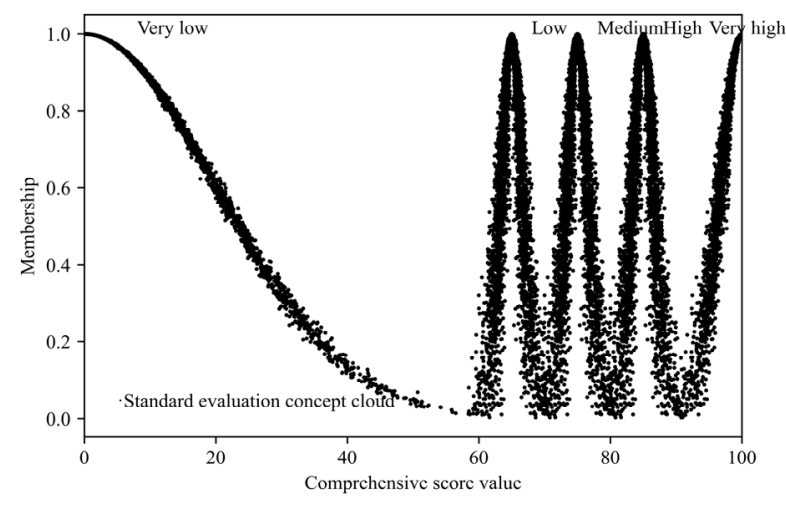

Figure 1. Standard evaluation concept cloud

\section{Empirical analysis}

In this section, four provincial eletric power companies are selected to verify the proposed risk assessment model for electricity transmission and distribution price regulation of power grid enterprises. Equations should be centred and should be numbered with the number on the right-hand side.

\subsection{Determine index weights}

After getting seven risk criteria, the expert panel was invited to score the weight of the index system. The best criterion was the electricity transmission and distribution cost implementation deviation risk (C4), and the worst criterion was the enterprise operational risk (C6). The scores of each criterion relative to the best and worst criterion are shown in Table 3 and Table 4.

Table 3. Comparison results between the optimal criterion and other criteria

\begin{tabular}{cccccccc}
\hline The optimal & \multicolumn{7}{c}{ Criteria } \\
\cline { 2 - 8 } criterion & $\mathrm{C} 1$ & $\mathrm{C} 2$ & $\mathrm{C} 3$ & $\mathrm{C} 4$ & $\mathrm{C} 5$ & $\mathrm{C} 6$ & $\mathrm{C} 7$ \\
\hline $\mathrm{C} 4$ & 5 & 3 & 3 & 1 & 2 & 6 & 4 \\
\hline
\end{tabular}

Table 4. Comparison results between the worst criterion and other criteria

\begin{tabular}{cccccccc}
\hline \multirow{2}{*}{$\begin{array}{c}\text { The worst } \\
\text { criterion }\end{array}$} & C1 & C2 & C3 & C4 & C5 & C6 & C7 \\
\cline { 2 - 8 } & 2 & 3 & 4 & 7 & 5 & 1 & 3 \\
\hline
\end{tabular}


The weight is calculated to be $\mathrm{w}=(0.07,0.13,0.13$, $0.29,0.24,0.04,0.09)$. Meanwhile, $\mathrm{CR}=0.21$, which satisfies good consistency. The calculation process is realized by software LINGO 17.0.

\subsection{Comprehensive cloud risk assessment}

Table 5 shows the evaluation of each index of four provincial power companies. By multiplying the index level range with the index weight, the comprehensive cloud level of four provincial power companies can be obtained, as shown in Figure 2. The result is implemented by Python 3.8.

Table 5. Index performances of four provincial power companies

\begin{tabular}{lllll}
\hline & Enterprise 1 & Enterprise 2 & Enterprise 3 & Enterprise 4 \\
\hline C1 & High & High & High & Very high \\
C2 & Medium & Medium & High & High \\
C3 & High & Very high & Low & Medium \\
C4 & Very high & Medium & Medium & High \\
C5 & Medium & Medium & High & Medium \\
C6 & High & Very high & High & High \\
C7 & Low & High & High & Medium \\
\hline
\end{tabular}

According to calculation result, the digital characteristics of enterprise 1 are $(87.5,2.13,0.5)$, and the corresponding integrated cloud in Figure 2 is red. The digital characteristics of enterprise 2 are $(83.71,1.93,0.5)$, and the integrated cloud in Figure 2 is blue. The digital characteristics of enterprise 3 are $(79.44,1.65,0.5)$, the comprehensive cloud in Figure 2 is orange, and the risk level is between medium and High.The digital characteristics of enterprise 4 are $(82.64,1.77,0.5)$ corresponding to the integrated cloud in Figure 2 is green. It can be concluded that the order of risk levels of all companies in descending order is: Enterprise $1>$ Enterprise $2>$ Enterprise $4>$ Enterprise 3. Therefore, Enterprise 1 has the highest risk, and Enterprise 3 has the lowest risk. For the electricity transmission and distribution tariff supervision, the electric power companies should pay more attentions to the electricity transmission and distribution cost implementation deviation risk and grid investment execution deviation risk, and take effective measures to improve their ability to avoid risks.

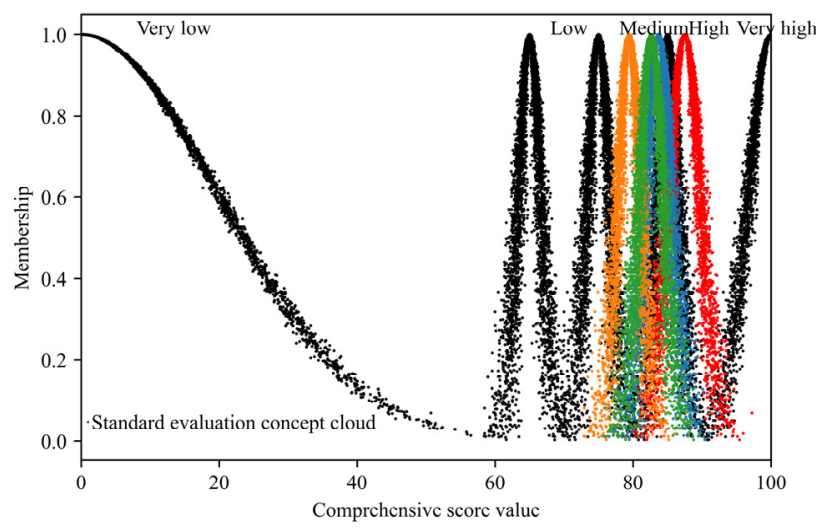

Figure 2. Integrated cloud of electric power companies

\section{Conclusion}

Based on the best-worst method and the normal cloud model, this paper constructed a risk assessment model for power transmission and distribution tariff regulation of power grid enterprises, and took four provincial power grid enterprises as examples for empirical analysis. The result shows that Enterprise 1 has the highest risk, followed by Enterprise 2, Enterprise 4, Enterprise 3. Only Enterprise 3 is at the upper middle level, while the other three enterprises are near "high" level. Currently, the electric power companies should pay more attentions to the electricity transmission and distribution cost implementation deviation risk and grid investment execution deviation risk. With the continuous improvement of electricity transmission and distribution price regulation policies, the risk evaluation index system of electricity transmission and distribution price regulation for power grid enterprises constructed in this paper can be updated according to the actual situation. The risk assessment model proposed in this paper can also be used for other risk assessment issues related to power grid enterprises, such as investment supervision risk assessment of power grid enterprises.

\section{Acknowledgments}

This research was funded by the project "Theory, technology and application on regulatory risk management and information disclosure of power grid enterprises under electricity transmission and distribution tariff reform" of the Science and Technology Project of the State Grid Corporation of China (1400201957285A-0-0-00).

\section{References}

1. C. Li, P. Li, X. Feng, Renewable Energy. 64, 266 (2014)

2. I.T. Pop, F. Raducanu, C. Munteanu, Acta Electrotehnica. 56, 272(2015)

3. J. Rezaei, Omega. 53, 49(2015)

4. S. Guo, H.R. Zhao, Knowl.-Based Syst. 121, 23 (2017)

5. Q. Ye, S.W. Li, Y.H. Zhang, Computer Engineering and Design., 32(12):4198 (2011)

6. B. Guo, W.Q. Zang, X. Yang, Sci. Total Environ. 746, 141(2020) 